\title{
LAS COMBINACIONES SALITRERAS: EL SURGIMIENTO DEL EMPRESARIADO DEL NITRATO EN CHILE (1884-1910)*
}

\author{
NITRATE COMBINATIONS: THE EMERGENCE OF THE NITRATE \\ ENTREPRENEURS IN CHILE (1884-1910)
}

\author{
Sergio González Miranda**
}

\begin{abstract}
Las combinaciones salitreras han sido vistas como una forma de organización voluntaria de los empresarios salitreros para controlar la producción del nitrato de soda y obtener mejores precios en el mercado internacional de los fertilizantes. A partir de esa estrategia, que tuvo más o menos éxito entre 1884 y 1910, se habrían conformado las principales organizaciones salitreras: el Comité Salitrero, el Nitrate Permanent Committee y la Asociación Salitrera de Propaganda. Sin embargo, no se ha puesto suficiente atención en su importancia como aglutinador de dicho empresariado hasta transformarlo en uno de los grupos (sindicato o trust) más influyentes de la economía nacional en dicho periodo.

Detrás de las combinaciones salitreras estuvo el intento explícito de este grupo empresarial, liderado por los industriales ingleses, por alcanzar el monopolio de la exportación del nitrato chileno sin la necesidad de realizar grandes innovaciones tecnológicas. Por lo mismo, en la organización de las combinaciones está la clave para entender el éxito y fracaso de la industria del salitre durante las décadas de mayor auge dentro del ciclo de expansión del nitrato.
\end{abstract}

Palabras claves: combinación salitrera, sindicato empresarial, monopolio, economía salitrera.

Nitrate combinations have been seen as a way of voluntary organization of nitrate entrepreneurs to control the production of nitrate and obtain better prices in the international market of fertilizers. Since that strategy, that was relatively successful between 1884 and 1910, the main nitrate organization would have been constituted: the Comité Salitrero, the Nitrate Permanent Committee and the Asociación Salitrera de Propaganda. However, they have not paid enough attention to its importance as a cohesive of that management till changing it into one of the most influential groups (union or trust) of the national economy in that period. Behind the nitrate agreements there was an explicit attempt of this business group, led by the English industrialist, to reach the monopoly of exportation of Chilean nitrate without making intense technological innovations. Therefore, the key to understand the success and failure of the nitrate industry during the decades of biggest boom within the expansion cycle of nitrate is in the organization of combinations.

Key words: nitrate combination, employers' unions, monopoly, nitrate economy.

\section{Introducción}

Una de las formas de organización que caracterizaron -a partir de la década de 1880- al empresariado salitrero fueron las combinaciones, las que tenían por objetivo inmediato definir las cuotas de producción de nitrato de soda por oficinas ${ }^{1}$, para evitar una sobreproducción y asegurar un alto precio en el mercado internacional de los fertilizantes. El control de la producción fue, en general, exitoso, pero ello no aseguró siempre los mejores precios del nitrato chileno, al contrario, incentivó la competencia de otros fertilizantes como el sulfato de amonio, los abonos compuestos, la cianamida o cal azoada, el nitrato de Noruega, entre otros. De hecho, desde una mirada amplia, esta estrategia durante el siglo diecinueve podría calificarse de fracasada, porque los mejores precios recién se obtuvieron a partir del siglo siguiente, pero solo por una década, pues las combinaciones desaparecieron hacia 1910, cuando el capital inglés inició lentamente su retirada de este negocio, mientras la economía del nitrato hacia 1914 se dirigía hacia una crisis inevitable ${ }^{2}$. Por lo mismo, las combinaciones solo existieron en el contexto del mercado de los fertilizantes y no de otros, como el mercado del salitre refinado para explosivos durante la Primera Guerra Mundial, donde se alcanzó alta demanda y mejores precios debido a un factor externo inesperado.

A pesar de que entre 1884 y 1910 hubo más años de combinaciones que de producción libre de salitre (ver Cuadro 1), esta forma de colusión del empresariado salitrero ha sido estudiada generalmente desde una perspectiva exclusivamente económica

* Resultado Proyecto Fondecyt 1100074.

** Universidad Arturo Prat, Instituto de estudios Internacionales (INTE), Iquique, Chile. Correo electrónico: sgonzale@unap.cl 
y no sociológica. No se han respondido preguntas sobre el sentido político de esta organización, su alcance sociológico, y el por qué de su emergencia y desaparición.

Cuadro 1. Exportación de salitre según tipo de acuerdo de producción de salitre. ${ }^{3}$ Los años referidos marcan el cambio de acuerdo.

\begin{tabular}{ccc}
\hline Año & $\begin{array}{c}\text { (Toneladas } \\
\text { métricas) }\end{array}$ & $\begin{array}{c}\text { Tipo de organización } \\
\text { de la producción }\end{array}$ \\
\hline 1880 & 223.974 & Libre \\
1884 & 558.720 & $1^{\circ}$ Combinación \\
1884 & & Comité Salitrero \\
1886 & & Nitrate Permanent Committee \\
1887 & 704.244 & Libre \\
1891 & 789.312 & $2^{\circ}$ Combinación \\
1894 & 1.098 .454 & Libre \\
1894 & & Asociación Salitrera de Propaganda \\
1896 & 1.107 .045 & $3^{\circ}$ Combinación \\
1898 & 1.293 .947 & Libre \\
1901 & 1.259 .720 & $4^{\circ}$ Combinación \\
1906 & 1.656 .088 & $5^{\circ}$ Combinación \\
1911 & 2.449 .515 & Libre \\
1919 & 915.239 & Asoc. Productores \\
1927 & $2.377 . .831$ & Libre \\
1929 & 2.898 .141 & Nueva Asoc. \\
1931 & 1.425 .996 & Cosach \\
1933 & 705.958 & Corp. Ventas \\
& & Covensa \\
\hline
\end{tabular}

¿Qué sentido tuvieron entonces las combinaciones? Nuestra hipótesis propone que, si bien el objetivo de definir cuotas de producción por oficina salitrera para lograr un mejor precio del nitrato en el mercado internacional de los fertilizantes pudo ser verdadero, hubo también otras finalidades que fueron más eficientes y con mayor alcance para el empresariado salitrero. Lo principal fue tener un motivo de unidad empresarial que terminará por consolidar un sindicato ${ }^{4}$ empresarial, que se expresó en el Nitrate Permanent Committee, que tenía sede en Londres, y la Asociación Salitrera de Propaganda, con sede en Iquique. Si los empresarios salitreros tenían como principal objetivo controlar el precio internacional del nitrato de Chile, ¿por qué se concentraron solamente en factores internos, como definir cuotas de producción, y no pusieron atención a factores externos que estaban directamente relacionados con el mercado de consumo de los fertilizantes, como la competencia de otros productos azoados y la existencia de intermediarios y especuladores que hacían fluctuar peligrosamente el precio del salitre en los mercados de destino?
El principal argumento que los organizadores de las combinaciones utilizaron fueron las recurrentes crisis, algunas plenamente justificadas y otras muy discutibles. La primera fue la caída del precio del azúcar hacia 1884 que dio origen a la primera combinación. Sin embargo, postulamos que la combinación sirvió como acicate para aglutinar a un empresariado que, en la década de 1880 , se desarrolló en medio de un entorno hostil debido, por un lado, a las presiones políticas y legales ejercidas al Estado chileno por los tenedores de bonos que no accedieron a oficinas salitreras o estacamentos ${ }^{5}$ $y$, por otro, a la incertidumbre en torno a la política salitrera que habría de decidir el Gobierno chileno de época.

En la conformación del Comité Salitrero en 1884 se tuvo la convicción empresarial que se estaba frente a una oportunidad única de acceder al monopolio del nitrato de Chile (Schmidt 1884:4). Fue esta la razón principal de la combinación y, para ello, era preciso que nadie rompiera la colusión. Es por este motivo que se optó por formalizar la combinación en las notarías de los puertos salitreros.

Fue esa capacidad de aglutinación que les permitió a los empresarios salitreros tener una sola voz frente a los gobiernos nacionales, a sus críticos y al movimiento obrero. Estuvieron unidos bajo las difíciles circunstancias de la Guerra Civil de 1891, año en que iniciaron la segunda combinación; recibieron a la primera Comisión Consultiva destinada a estudiar los problemas sociales de las regiones salitreras en 1904, redactando un Memorial de los patrones como respuesta a los diversos memoriales presentados por los trabajadores del salitre al Gobierno de Germán Riesco, liderados por la Combinación Mancomunal de Obreros (Reyes 1973); en plena quinta combinación, en diciembre de 1907, enfrentaron el mayor movimiento huelguístico de todo el ciclo del nitrato, con efectos económicos menores para esta industria. El factor externo que tuvo el mayor impacto en el empresariado salitrero, fracturándolo, fue la Guerra Mundial de 1914, cuando las combinaciones ya habían dejado de funcionar.

Sostenemos, entonces, que las combinaciones fueron clave en la formación del empresariado salitrero como organización y ethos ${ }^{6}$. En las décadas anteriores a 1880, en Taltal y el Toco, la economía salitrera estaba recién en la fase de exploración y de incipiente industrialización, en Antofagasta había solamente una oficina salitrera que podía ser calificada como una industria ${ }^{7}$. En Tarapacá había una 
cantidad significativa de industrias con una importante agrupación de empresarios salitreros. Sin embargo, enfrentaron la década de 1870 diversos litigios con los gobiernos peruanos de Manuel Pardo y Mariano Ignacio Prado, incluyendo una ley de expropiación (1875), que terminó por desarticularlos. Las acciones tomadas por este grupo de empresarios frente a los Gobiernos del Perú no fueron exitosas (González 2010), llevando a las grandes casas salitreras como Gibbs o Gildemeister, entre otras, a negociar por separado. Fue, por lo mismo, durante el periodo de la administración chilena, a partir de 1884, cuando se inició el proceso de consolidación del empresariado que proyectará el ciclo de expansión del nitrato hasta 1913.

El esfuerzo asociativo de los industriales salitreros que, en menos de una década, habían vivido un complejo proceso de expropiación y recuperación de oficinas, fue destacable, considerando que esta industria no estaba concentrada en un pequeño territorio o en pocas manos. Al contrario, las oficinas salitreras estaban esparcidas en diversos cantones entre los paralelos $19^{\circ} 35^{\prime}$ y $25^{\circ} 30^{\prime}$ Sur. Respecto del número de oficinas salitreras, hemos anotado 48 en 1884 (ver Cuadro 3), una década después en 1894, Cariola y Sunkel (1991) registran 51. Un año de mayor consolidación, 1899, previo al cambio de siglo, según la Asociación Salitrera de Propaganda, este era el orden desde Tarapacá hasta Taltal.

\section{Cuadro 2. Oficinas salitreras y su producción de salitre en quintales españoles en 1899.}

Mercedes

North Lagunas

592.675

Puntunchara

289.340

Progreso

Providencia

43.036

124.950

Ramírez

572.680

Reducto

115.056

Rosario de Huara

435.380

169.161

115.071

108.100

366.160

94.372

59.140

463.680

449.650

84.540

$\begin{array}{ll}\text { Sacramento de Z. } & 84.540 \\ \text { Santa Rita } & 43.166\end{array}$

Santa Lucía

243.340

Santa Rosa de Huara

192.777

125.704

147.414

150.190

344.061

215.510

216.342

658.500

15.193

Vis

266.280

ANTOFAGASTA

Antofagasta

\section{TOCOPILLA}

Buena Esperanza $\quad 353.468$

Peregrina

294.124

Santa Isabel del Toco $\quad 239.885$

Santa Fé del Toco $\quad 260.682$

Iberia de Sáez

338.480

TALTAL

Atacama $\quad 115.796$

Lautaro $\quad 217.743$

Santa Luisa $\quad 558.633$

Fuente. Asociación Salitrera de Propaganda, 1899.

Coincidiendo con el Cuadro 2, Cariola y Sunkel (1991:126) registran 58 oficinas salitreras para 1899, sin embargo, vemos que no todas ellas produjeron ese año debido a la combinación.

Las combinaciones, en lo formal, fueron, según Enrique Reyes, "una asociación voluntaria de productores de nitrato de soda, que se relacionan entre sí por un vínculo jurídico de carácter privado y que tiene por objeto el control intencional de la producción anual de nitrato con relación al mercado consumidor. Esta asociación voluntaria es de 
limitada duración en el tiempo, generalmente no más de tres años, renovable por acuerdo entre las partes" (1985:185). Cabe agregar que era necesario que todos los productores estuvieran de acuerdo para que la combinación se llevara a cabo, lo que podría calificarse como una debilidad o fragilidad de esta asociación; sin embargo, fue también su fortaleza, porque obligó a la organización a extremar sus capacidades de negociación, convencimiento y de atracción. En cierta forma hubo hegemonía y violencia simbólica (Bourdieu 1970) entre el empresariado ejercidas desde la cúpula del Comité Salitrero, primero, y desde el Nitrate Permanent Committee y la Asociación Salitrera de Propaganda, después, a través de las combinaciones.

Estas capacidades irán incrementándose desde 1884 hasta que las combinaciones llegaron a constituirse en un verdadero Sindicato, Trust o Cartel empresariales, más allá que se alcanzara o no la finalidad de influir en el precio del nitrato de soda en el mercado internacional de los fertilizantes. Otra fortaleza que emergió a partir de la organización de las combinaciones fue un aumento de la densidad en las relaciones comerciales y sociales entre los asociados, como se puede concluir al analizar las fuentes notariales entre 1900 y 1913 acopiados por la Asociación Salitrera de Propaganda y conservados en el Archivo Histórico Nacional (en adelante AHN), Fondo del Salitre, Documentos Notariales, especialmente durante las tres últimas combinaciones. Por lo anterior, las combinaciones tuvieron una importancia no solo económica, sino también política y sociológica. En otras palabras, se aproximaron a lo que sociológicamente se entiende como una institución, en el sentido que también expresó no solo una forma de organización y un tipo de pensamiento económi$\mathrm{Co}^{8}$, sino en un complejo de valores que orientó el quehacer de los asociados respecto de su actividad económica e, incluso, en determinados momentos, también más allá de sus límites, influyendo en otros campos, como el político.

Enrique Reyes Navarro plantea que "quienes se beneficiaban más directamente en el seno de la combinación eran los productores de altos costos, que en condiciones de libre producción podían ser supeditados por los sectores de la industria que producían a costos medios y bajos. Productores de altos costos los había de todas las nacionalidades, excepto quizás la parte alemana" (1985:187). Este razonamiento nos debería llevar a concluir que los pequeños productores, las oficinas con tecnologías más antiguas o aquellas con caliches de menor calidad, serían las más beneficiadas por la combinación, pues tendrían los costos más altos. Es dudoso que ese beneficio se debiera a un altruismo por parte de las Compañías poseedoras de la tecnología o del capital, cobijando en el seno de la combinación a los salitreros más débiles o ineficientes. Más bien, sostenemos, respondía a intereses mutuos que iban más allá de los estrictamente económicos. Ya desde 1893, los críticos a las combinaciones se referían a la escasa innovación tecnológica de la industria salitrera, no imaginaron que ese problema se extendería hasta la segunda década del siglo XX. Precisamente hacia 1910, último año de combinación, y fecha simbólica en Chile, donde se levantan voces críticas hacia la economía y sociedad nacionales, Alejandro Bertrand expuso con detalle el problema y la competencia que enfrentaba el nitrato de Chile en el concierto internacional (1910:42 sgtes). Sin embargo, la emergencia del mercado de salitre refinado para explosivos producto de la Primera Guerra Mundial, postergó todas esas aprensiones hasta 1920. Una tardía reacción por mejorar los procesos productivos, aumentar la productividad e innovar en tecnologías permitió la introducción de un nuevo sistema de lixiviación de nitrato denominado Guggenheim, iniciativa norteamericana. En otras palabras, durante el periodo de las combinaciones, la escasa inversión en tecnología benefició tanto a las grandes casas salitreras como a los pequeños productores.

\section{La primera combinación salitrera}

La primera combinación se inauguró en junio de 1884 organizada por el Comité Salitrero que se había fundado unos meses antes. Las casas salitreras que formaron parte de esta combinación fueron: en Valparaíso: Banco Mobiliario, Döll y $\mathrm{C}^{\circ}$; en Taltal: Daniel Oliva; puerto Oliva: A. Quaet Faslem; Antofagasta: Compañía de Salitres y Ferrocarril de Antofagasta; Tocopilla: Sáez y Lara; Iquique: Otto Hermann, José Devescovi, Rodolfo Boivin, Genrao Canelo, Compañía Salitrera Progreso, Goich Zayas y $\mathrm{C}^{\circ}$, J. Gildemeister y $\mathrm{C}^{\circ}$, North y Harvey, Compañía Salitrera Liverpool, Ugarte Cevallos y $\mathrm{C}^{\circ}$, Fölsch y Martin, Banco Mercantil Internacional, Juan Marincovich, Retzlaff Charme y $\mathrm{C}^{\circ}$, Eck Trevor y $\mathrm{C}^{\circ}$, Barreda y Schröder, L. Cevallos y $\mathrm{C}^{\circ}$; Pisagua: Eujenio Labernadie, Pedro Perfetti, Loayza y Pascal, J.T. Humberstone y $C^{\circ}$, J. Sanguinetti y 
$\mathrm{C}^{\circ}$, Kraljevic Hnos., Campbell Outram y $\mathrm{C}^{\circ}$, G. E. Brooking, Nicolás Zeballos, Kraljevich, Zvetcovich y $C^{\circ}$; Tacna: Devés Fréres, Suc. J. Layous y $C^{\circ}$.

El presidente del Comité Salitrero, H.G. Schmidt, en su Memoria del 8 de noviembre de 1884, planteó los criterios fundamentales de la primera combinación. Señala en dicha memoria que "vencidos los naturales recelos que entre los industriales había hecho nacer el réjimen de libre competencia i bien poseídos de la idea de que ella nos llevaba a una crisis violenta se formuló el acuerdo de 10 de Junio del corriente año con el objeto de limitar la producción..." (1884:51). Es decir, no era competencia con otros fertilizantes los que le preocupaban al Comité Salitrero, sino la que podría surgir entre los propios empresarios del nitrato chileno, por lo tanto, el mayor temor era que el Gobierno del Presidente Domingo Santa María iniciara nuevos remates de salitreras y estacamentos después de los realizados en virtud del decreto del 31 de julio de $1882^{9}$. Esta mirada "hacia adentro" fue la que inspiró la combinación más que el mercado internacional.

El objetivo del Comité Salitrero era lograr que, por un lado, el Gobierno no amenazara sus intereses $\mathrm{y}$, por otro, los tenedores de bonos peruanos al portador no lograsen su objetivo de acceder a salitreras o estacamentos nuevos. El decreto del 28 de marzo de $1882^{10}$, clave para el rescate de las salitreras compradas por el Gobierno peruano en virtud de la ley de expropiación de 1875, dejó explícitamente fuera de esa posibilidad a los tenedores de bonos o certificados al portador. Los salitreros que efectivamente accedieron a la industria calificaron de "especuladores" a estos tenedores. Por lo anterior, es que Hermann G. Schmidt, en la Memoria ya citada, afirma, por una parte, que "contamos con el decidido apoyo del Gobierno de Chile, con el convencimiento i la voluntad de todos los productores de salitre i con el buen sentido de los capitalistas, que no se aventurarán á ponernos en dificultad, esponiendo sus propios intereses á una pérdida segura" y, por otra, "tampoco debemos abrigar el temor de que á la sombra de nuestros sacrificios vengan especuladores á dar vida á nuevos establecimientos de producción, sin aceptar las bases de nuestro acuerdo, porque estará siempre en nuestras manos causarles su inmediata ruina" (Schmidt 1884:53). En otras palabras, en la unión o sindicato estaba el poder frente a unos y otros, un poder que surgió desde el momento en que todos los salitreros firmaron ante notario aceptar los términos de la primera combinación. "Debemos, pues, felicitarnos de habernos acercado y reunido: conocemos ya nuestro poder i sabemos que el bienestar de nuestra industria depende exclusivamente de nuestra prudencia..." (Schmidt 1884:53). De esa forma surge el empresariado del salitre en Chile.

La mirada "desde fuera" a la creación de la primera combinación nos la entregan Semper y Michels: "la decadencia de la industria azucarera en Europa trajo una disminución del consumo del salitre i amenazó la industria salitrera con una crisis terrible que fue conjurada por los productores con la formación, en junio de 1884, de un sindicato para limitar la producción llamado de la 'Combinación Salitrera"” (1908:141). Los traductores de estos autores alemanes (Javier Gandarillas y Orlando Ghigliotto) afirman "que se fijó en esta combinación una cuota a 36 oficinas ubicadas en Tarapacá, 1 en Tocopilla, 2 en Antofagasta y 5 en Taltal" (N. de los T.) (1908:141), lo que no coincide exactamente con lo que hemos registrado del Comité Salitrero (ver Cuadro 3).

El siguiente cuadro expresa las oficinas comprometidas por la combinación según las casas salitreras.

Cuadro 3. Oficinas salitreras y sus propietarios combinados en 1884.

\begin{tabular}{ll}
\hline \multicolumn{1}{c}{ Productores } & \multicolumn{1}{c}{ Oficinas } \\
\hline Juan Marincovich & San Donato \\
North y Harvey & Peruana \\
Ídem & Buen Retiro \\
Liverpool Nitrate $C^{\circ}$ & Ramírez \\
Ugarte, Ceballos i C & San Lorenzo \\
Rodolfo Boivin & Rosario \\
José Devéscovi & Constancia \\
Loayza i Pascal & Ánjela \\
Kraljevic Hnos. & Mercedes \\
J.T. Humberstone y C & Tres Marías \\
Eck, Trevor y C & Esmeralda \\
Compañía Progreso & Progreso \\
J. Sanguinetti y C & Puntunchara \\
Fölsch y Martin & Virjinia \\
Ídem & Paposo \\
Ídem & Peña Chica \\
Ídem & Sacramento \\
Ídem & San Carlos \\
Banco Mobiliario & Cala Cala \\
J. Gildemeister y C & San Juan \\
Ídem & Arjentina \\
Ídem & San Pedro \\
Barreda y Schröder & San Pablo \\
Campbell, Outran y C & Agua Santa \\
&
\end{tabular}




\begin{tabular}{ll}
\hline \multicolumn{1}{c}{ Productores } & \multicolumn{1}{c}{ Oficinas } \\
\hline E. Labernadie & Cordillera \\
G.E. Brooking & Santa Rita \\
Pedro Perfetti & Camiña \\
Otto Hermann & Santa Beatriz \\
Gibbs i C & Patria \\
Ídem & Jazpampa \\
Ídem & Palma \\
Goich, Zayas y C & Solferino \\
Genaro Canelo & San Fernando \\
Retzlaff, Charme y $C^{\circ}$ & Amelia \\
Nicolás Zeballos & San José \\
Banco Mercantil & Yungai Bajo \\
Layous y C & Bearnés \\
C $^{\circ}$ de Antofagasta & Antofagasta \\
Döll y C & Esmeralda \\
Ídem & Florencia \\
Daniel Oliva & Lautaro \\
Ídem & Santa Catalina \\
Ídem & Bella Vista \\
Ídem & Chilena Española \\
Keating \& Quaet Faslem & \\
Sáez i Lara & Buena Esperanza \\
\hline
\end{tabular}

Fuente: Comité Salitrero, Iquique, junio 10 de 1884 (Schmidt 1884:33).

Estos fueron los empresarios que crearon la estructura de lo que sería después el empresariado salitrero, en lo que se conocería como "el ciclo de expansión" durante la administración chilena de esta economía. Notoriamente existe una gran diferencia entre las diversas "casas salitreras", algunas estaban más próximas a la desaparición o eran tecnológicamente muy precarias, y otras respondían a un capitalismo en la periferia moderno, equipadas con la mejor tecnología del momento. Por lo tanto, ¿qué les unía?, ¿por qué evitar la competencia entre ellas?

J.T. North lideró desde Londres esta combinación y la siguiente, hasta que lo sorprendió la muerte en 1896 justo cuando se iniciaba la tercera combinación salitrera. Fueron precisamente esas tres combinaciones las que menos impacto tuvieron en la venta de nitrato de soda en el mercado internacional, pero fueron la pátina de la economía salitrera futura.

La Primera Combinación concluyó el 31 de diciembre de 1886, de inmediato se aumentó la exportación de salitre de 9.790 .000 a 15.300 .000 quintales, especialmente debido a la gran capacidad productiva de empresas inglesas. Hacia 1884 Agua Santa, de Campbell, Outran y $\mathrm{C}^{\circ}$, y Ramírez, de Harvey y North, eran las de mayor proyección productiva. A pesar de los vientos favorables en el mercado, los precios del salitre chileno tuvieron hacia fines de esa década una leve tendencia a la baja.

\section{La segunda combinación}

La segunda combinación entró a regir el $1^{\circ} \mathrm{de}$ enero de 1891, cuando los vientos de Guerra Civil ya comenzaban a sentirse en Chile, por lo mismo, fue la más resistida de todas, especialmente porque se asoció a este conflicto a la economia salitrera y, en particular a la fugura de J.T. North. La propia Guerra Civil afectó a la producción de ese año, pero no a la combinación misma que duró hasta el 31 de marzo de 1894. Dos días antes de expirar, el 29 de marzo de 1894, en Iquique se fundó la Asociación Salitrera de Propaganda, que supuestamente duraría tres años, pero que siguió funcionando en forma interrumpida hasta el 10 de enero de 1919, cuando se crea la Asociación de Productores de Salitre de Chile, cambiándose la sede a Valparaíso.

Posiblemente la figura más emblemática de los contrarios a este sTrust fue Francisco Oliván. Curiosamente en la Junta Directiva del Comité Salitrero de junio 10 de 1884 parecen como presidente, H.G. Schmidt; vicepresidente, J.M. Inglis; propietarios J. Goich, A. Brinckfeldt, J.J. Loayza, F.A. Oliván, T.D.Whitelegg, J. Devéscovi, L.G. Gallagher. Se trata, entonces, ni más ni menos que un empresario que formó parte del círculo más estrecho de los creadores de las combinaciones salitreras.

A pesar de ello, en 1893, señalaba Oliván: "la Combinación Salitrera dentro de los límites moderados, ha podido satisfacer un fin lícito; pero salir de estos límites, para llegar al abuso, es justificar al Gobierno si toma medidas para evitar que hagamos daño a sus intereses. La Combinación Salitrera, en su segunda edición, ha sido y es más especuladora que industrial.

Así lo he dicho y he repetido desde el principio y he desconfiado del Círculo de Londres. El Directorio se compone de representantes de la compañía inglesa y salitreros de costa; es decir, que no hay unidad de miras como hubo en la anterior Combinación, y como debe haber en una asociación de esta clase" (1893:4). ¿Por qué califica Oliván de especulativa a una colusión empresarial que no alcanzó sus fines explícitos? Bertrand es claro en este sentido: "los efectos de la segunda combinación (1890) aunque agravados luego por la revolución de 1891, fueron menos perceptibles en el precio que los de la $1^{\mathrm{a}}$, y el aumento en la exportación que le siguió después de 1893 es muy acentuado. La tercera combinación no produjo ningún aumento del precio..." (1910:13). En otras palabras, la combinación debió tener otros 
fines distintos al precio del nitrato en el mercado mundial de los fertilizantes, que fueron tanto o más importantes que este, Oliván lo observa en el "Círculo de Londres", es decir, el Nitrate Permanent Committee digitaría desde la "City" el devenir de la economía salitrera.

Apunta también sus dardos hacia J. T. North, "North, a la sombra de una Combinación que tiene por objeto reducir la elaboración a seis meses en el año, planifica grandes maquinarias en Lagunas; y esto demuestra claro, sin más consideraciones que ilustren, el resultado después. Una Combinación que tiene por fin aparente ayudar al salitrero productor para que no se arruine, y que en realidad es para encubrir infladuras, tender engañosas e hipócritas redes para producir encerronas, ha de traer, fatalmente, situaciones críticas y ruinosas para el país, porque no se piensa en remediar el mal, sino en engañar con un alivio transitorio, para después sufrir mucho más que antes. Hasta qué punto puede un Gobierno salvar la responsabilidad de no haber puesto la mano para evitar en lo posible un mal que puede ser de trascendencia, por el respeto a una libertad, tal vez ilimitada, se verá después, cuando venga el arrepentimiento, de no haberlo hecho..." (1893:15). Contrariamente a lo afirmado por Oliván, las combinaciones no trajeron la ruina al país, pero tampoco se puede afirmar que hayan sido una palanca de desarrollo de esta economía. Se podría aseverar, en cambio, que evitó la competencia y la innovación tecnológica y, por lo mismo, acortó el ciclo de expansión. La Primera Guerra Mundial extendió un ciclo económico que ya mostraba signos de agotamiento hacia 1913.

Como Oliván, hubo un personaje de talla no menor en asuntos salitreros que salió en defensa de las combinaciones, Gonzalo Bulnes, quien fuera, en el marco del Tratado de Ancón, el primer Intendente de Tarapacá, además de destacado historiador. Definía Bulnes a la combinación en 1887, de forma metafórica: "La Combinación es una tienda de campaña en que se guarecen los industriales un día de desecho temporal. Cuando todo amaga la industria, la unión de los interesados es lo único que puede restablecer el equilibrio perdido entre la producción ilimitada i el consumo limitado. Sobre esa tienda se levanta la bandera blanca: la bandera de la tregua industrial. Allí se cobijan las casas opulentas i las humildes: el grande i el pequeño capital: la poderosa máquina que produce la décima parte del consumo i otra que tiene pequeña capacidad industrial" (La Libertad
Electoral sábado 23 de abril de 1887). Parece, en esa imagen, como una organización solidaria, un paraguas temporal mientras acontecen chubascos, que en la economía salitrera los empresarios denominaban "crisis", sin embargo, no imaginaría Bulnes que entre 1884 y 1910 habría más años de combinación que de libertad empresarial.

Dado que Bulnes escribe durante el Gobierno de J.M. Balmaceda, señala: "No quiero ocuparme por ahora de examinar las medidas que, según el rumor público, medita el gobierno para nacionalizar la riqueza de Tarapacá. A ser cierto lo que se dice, ellas echarían por tierra la industria chilena establecida en Taltal i en Antofagasta; pondrían en serio peligro el capital chileno de los bancos repartido entre los salitreros i no conducirían sino a producir una lucha desastrosa en que todos saldrían perjudicados..." (La Libertad Electoral sábado 23 de abril de 1887). El antecesor de Bulnes en la primera magistratura provincial, Francisco Valdés Vergara, último Jefe Político de Tarapacá, pensaba igualmente que Bulnes y también fue contrario a Balmaceda, sin embargo, cambió de opinión de forma radical cuando observó la conducta monopólica y la colusión de los empresarios salitreros, llegando incluso a valorar el estanco peruano, afirmando que "el régimen fiscal peruano era bien concebido, armonizaba los intereses nacionales con la libertad de trabajo y no anulaba la iniciativa individual en esa industria" (1913:360). Igualmente cambiaría su opinión sobre la política económica de Balmaceda, refiriéndose al discurso de Iquique de 1889 de este presidente, donde tuvo la intención de "oponer resistencia a toda tentativa de concentrar las industrias en una sola empresa o en un monopolio privado. Estas palabras del Jefe de Estado, severas en el fondo y en la forma, dieron respuesta oficial a insinuaciones hechas por un afortunado organizador de sociedades salitreras en Londres que, desvanecido por el brillo de repentina riqueza, ambicionaba hacerse árbitro de la producción salitrera para dictar la ley tanto al mercado de acciones como al mercado de consumo. El intento era audaz, sobre todo por la influencia sin contrapeso que semejante combinación había de tener en las operaciones de cambio en Chile y en la renta fiscal, y el presidente estuvo a la altura de sus deberes condenándolo con energía" (Valdés 1913:362). En definitiva, la crítica principal de Valdés Vergara era la concentración económica que transformaba a este empresariado salitrero en “árbitro de la producción salitrera para dictar la ley 
tanto al mercado de acciones como al mercado de consumo" y, por lo mismo, también en árbitro de la renta fiscal. Curiosamente, Bulnes vio en ello un beneficio: "La Combinación tiene la considerable ventaja de fijar las rentas públicas. Determinándose de antemano el monto de la producción, el Estado que percibe por ella un impuesto fijo de tanto por quintal, tiene un punto de partida seguro para compajinar su presupuesto" (La Libertad Electoral, Viernes 22 de abril de 1887). Es evidente que, al ser las rentas generadas por el salitre las más significativas para el erario nacional, el poder político que desde ella emanaba era inconmensurable, más aún si quienes las generaban estaban unidos en un sindicato sólido y protocolizado, como lo exigía cada Combinación.

Existe una copiosa polémica periodística en torno a esta combinación, entre los periódicos $L a$ Libertad Electoral, El Heraldo, El Mercurio, El Nacional de Iquique, El Ferrocarril, La Patria, La Unión de Valparaíso, entre otros, donde participaron personajes como el propio Francisco Oliván, Oscar Salbach (Gerente de la casa salitrera Fölsch y Martin), Gustavo Jullian (delegado fiscal de salitreras), E. Vijil Z. (Gerente de la Combinación salitrera), L.C. Gallagher (directivo del Comité Salitrero), Alfredo Cocq Port, además de un personaje cuyo seudónimo era $\mathrm{XX}$, aparentemente un economista contrario a la combinación salitrera.

Esta interesante polémica que enfrentó a periódicos contrarios y favorables a la combinación salitrera y que abarca todos los años que duró esta segunda Combinación, gira fundamentalmente en torno a temas técnicos de producción y comercio, que por razones de espacio no podemos analizarlos. Solamente registrar algunos conceptos de Alfredo Cocq Port ${ }^{11}$, por ser el más decidido al plantear una política salitrera que iba en la dirección opuesta no solo a la de los empresarios, sino también a la del Estado de Chile.

Este autor proponía con audacia que el Estado fuera el único elaborador, transportador y vendedor de salitre, para ello se pregunta: ¿cuáles son, pues, las medidas que debemos por de pronto adoptar?, respondiéndose que debería "resolverse a no entregar a los particulares una pulgada mas de terreno salitral i a constituir al Estado en cooperador en la producción, elijiendo entre las oficinas que posee una ubicación conveniente para la fundación de un establecimiento regulador de una capacidad productora de 6 millones de quintales anuales". En otras palabras, por primera vez, durante la administración chilena se propone un estanco salitrero ${ }^{12}$, recordemos que el primer estanco salitrero se conoció en Tarapacá durante el Gobierno peruano de José Balta y se profundizó en el de Manuel Pardo.

Cocq Port, plantea que su propuesta tendría cinco ventajas:

“ $1 .^{\circ}$ Prevendría toda posibilidad de desarrollo del monopolio extranjero, sin herir los intereses lejítimos de los actuales productores; $2{ }^{\circ}$ Pondría en manos del gobierno letras que le permitirían regularizar el cambio impidiendo manejos perjudiciales por fluctuaciones de mera especulación; 3 . $^{\circ}$ Produciría al Estado utilidades suficientes para pagar los intereses i amortización del valor de los certificados salitreros i para el cuidado de las demás oficinas fiscales que vijilaría, también, de una manera eficaz, evitando todo robo de caliche, el personal del establecimiento de que hablamos; $4 .^{\circ}$ Seria un ensayo lleno de enseñanza práctica respecto a los inconvenientes i ventajas del sistema de esplotación directa por el Estado i formaría un personal idóneo en negocios salitreros; $5 .^{\circ}$ Por fin, sería una salvaguardia para las entradas fiscales en cualquier fluctuación desfavorable de los precio del salitre en los mercados europeos. Es evidente, en efecto, que en un descenso de precios considerable, cuando los demás productores se vieran obligados a reducir su producción limitándola al beneficio de los caliches de más alta lei, podría, aun, la oficina fiscal, restablecer el equilibrio en la cuantía de sus entradas entregando al mercado salitre cuyo costo podría disminuirse de todo el monto de la actual utilidad de los productores" (La Libertad Electoral, jueves 28 de febrero de 1889).

A pesar de la labor incansable y exitosa de la combinación por controlar la producción (y por añadidura la exportación) de salitre, hacia 1891, año en que se inicia la segunda Combinación ${ }^{13}$, se habían sacado de la región salitrera 250 millones de quintales españoles de salitre (Le Feuvre y Dagnino 1893:21), y la producción anual aproximada era de 20 millones de quintales españoles. Sin embargo, esta economía que estaba "controlada", que ofrecía ganancia a todos los "combinados" y también a 
muchos intermediarios, una vez iniciado el nuevo siglo comenzaría a dar señales de problemas de mercado.

Terminada la segunda combinación, no pasarían dos años de producción libre y se volvería a organizar una nueva bajo el argumento de una sobreproducción de salitre. Además, el mismo año que finalizó la segunda combinación uno de los mayores temores de los salitreros se hizo presente en el decreto del 9 de marzo de $1894^{14}$ : se ordenaba una subasta pública de 31 oficinas y 12 estacamentos de Tarapacá. Posteriormente el decreto de 31 de octubre de 1894 remataba 15 oficinas y 6 estacamentos más. Era imprescindible, entonces, para la recién fundada Asociación Salitrera de Propaganda, volver a combinarse con el objetivo de controlar la producción incluyendo a los nuevos propietarios.

\section{La tercera combinación}

El éxito de la combinación fue inmediato, Semper y Michels afirman que "después de entrar en vijencia la Combinación, el consumo superó la exportación. Pero, mientras tanto, había un gran stock del año anterior en Europa, a lo cual se agregó la competencia que hacía al salitre el sulfato de amoniaco, la decadencia de la industria azucarera (...), junto con las especulaciones a la baja de varias casas importadoras i de intermediarios que había realizado a tiempo sus existencias" (1908:143). Es por ello, que a pesar del eficiente método de cuotas de producción definidos por la combinación entre los productores de salitre, el impacto en el precio internacional de este fertilizante no bajó como se esperaba, porque no se controló con igual eficiencia la competencia de otros productos azoados, la previsión de crisis en los mercados de consumo y, especialmente, los especuladores e intermediarios que hacían subir o bajar los precios generando gran incertidumbre entre los consumidores del nitrato chileno, que terminaban por elegir a otros fertilizantes, como el sulfato de amonio, aunque en promedio fueran más caros o de menor calidad. ${ }^{15}$ El método escogido de equilibrar estos problemas fue la propaganda salitrera que, si bien fue eficaz, no fue suficiente. El Estado chileno compartió con la Asociación Salitrera de Propaganda los gastos de propaganda en los mercados de consumo. ${ }^{16}$

Esta combinación duró solamente dos años, rompiéndose en octubre de 1897, "a consecuencia del desacuerdo de los productores. Los años 1898 i 1899 presenciaron un considerable aumento de la exportación" (Semper y Michels 1908:144). Es interesante observar fisuras finiseculares en el empresariado salitrero, por lo mismo, los capitalistas ingleses intentaron "formar un Sindicato para la venta, compuesto por todos los productores reunidos. Un Comité formado por los mismos salitreros, bajo la dirección de la casa de Gibbs y C ${ }^{\circ}$ " (Semper y Michels 1908:144). Más allá del hecho que este Sindicato haya fracasado, quedó de manifiesto quiénes eran los más interesados en el control de la producción y exportación salitreras. La cuarta combinación recién comienza a organizarse con el inicio del nuevo siglo. De todos modos, al término de la tercera combinación, tanto el Nitrate Permanent Committee como la Asociación salitrera de Propaganda se habían transformado en organizaciones poderosas y muy influyentes, pero sobre todo sus asociados estaban estrechamente unidos por medios de compra y venta de salitreras, estacamentos y otras propiedades, como lo veremos en las siguientes combinaciones. En otras palabras, el empresario salitrero ya dejaba de ser emergente para transformarse en una red con densos vínculos comerciales y familiares.

\section{Cuarta y quinta combinaciones salitreras}

En 1901 comenzó la cuarta Combinación ${ }^{17}$, estableciéndose con claridad que el directorio de la Asociación Salitrera de Propaganda sería el mismo de la Combinación Salitrera (Combinación Salitrera 1900:3 sgtes). Ésta debió concluir en 1906, pero le continuará de inmediato una quinta, que se prolongará hasta 1910, demostrando una desesperación empresarial por evitar un periodo de libertad de producción. Esta medida no fue sin conflictos, como lo publicó el diario El Pueblo de Iquique, de propiedad del partido Demócrata, y que nos permite además registrar otra mirada sobre las Combinaciones.

\section{La combinación salitrera}

\section{Su Fracaso}

Diferencias entre los oficineros, motivadas porque cada cual quiere elaborar el mayor salitre posible, han traído como consecuencia la ruptura de la Combinación Salitrera, ó sea el fracaso de su renovación.

Para los salitreros, esto implica un daño en sus futuras negociaciones, porque roto el control de la producción, cada cual elaborará lo que quiera y venderá el precio 
que guste. En una palabra, se establecerá la competencia.

Para el Fisco, esto no significa nada, porque los derechos que percibe por el nitrato exportado, los recibe lo mismo con Combinación ó sin ella. Por el contrario, no existiendo, la exportación será mayor, ya que la elaboración, libre de toda traba, se hará en mayor escala.

Para los trabajadores, la cosa no es tan clara. Al principio, naturalmente, tendrán una buena época, porque como habrá mayor elaboración, se ocuparán más brazos en las faenas y subirán los salarios. Pero -y esto lo dicen los salitreros- la competencia de los precios en Europa, que depreciará grandemente el valor de esa sustancia, tiene que traer como consecuencia la paralización de algunas oficinas, y por supuesto, la falta de trabajo á muchos hombres.

Habrá entonces, en la Pampa, las siete vacas gordas y las siete flacas, de la Biblia, ó sea la abundancia, al principio, y después la escasez.

La situación porque atraviesan hoy los operarios de la Pampa, á quienes se pagan jornales miserables, desaparecerá, al trabajar con mayor fuerza las oficinas.

No existiendo la combinación, cesarán los enganches, ese inicuo sistema de abarrotamiento de brazos, y habrá para los pampinos, una época de bienestar; respirarán, después de tanta opresión.

$Y$ cuando paren algunos establecimientos, si es que suspenden sus faenas, la situación que se producirá no será nunca peor que la actual, en que á los operarios se les mantiene á ración de hambre, llenos de gabelas y amenazados de quedar sin trabajo, por la abundancia de brazos.

La alarma que, en los altos círculos comerciales ha producido la ruptura de la Combinación Salitrera, no tiene, pues, por qué conmover al elemento trabajador de la Pampa, puesto que los peores efectos de esa falta de acuerdo entre los oficineros, nunca serán como los que hoy sufren los esclavos de la Siberia Caliente.

Los afectados; son los de arriba; los de abajo, hace tiempo que están afectados.
Es esta la ley providencial, que señala á cada capa social sus grandezas y sus decadencias.

(Diario El Pueblo, Iquique, Jueves 7 de Diciembre de 1905).

Claramente, los demócratas del diario El Pueblo veían un beneficio en la libertad de producción y que los salitreros no estuvieran coludidos, mientras la “Combinación" los trabajadores (La Combinación Mancomunal Obrera) había tenido el año anterior su gran protagonismo, pero sin resultado alguno. Este es un punto que no se ha tratado en este artículo y que dice relación con la combinación y su impacto en el trabajo y en los movimientos sociales. Algunos de esos movimientos coincidieron con las últimas dos combinaciones: 1906 en Antofagasta y 1907 en Tarapacá. Sostenemos que la capacidad organizativa empresarial que se generó a partir de las combinaciones, les permitió a estos enfrentar a las demandas obreras (Vgr. Memoriales Obreros de 1904) unidos y con una seguridad temeraria. El principal conflicto que la historia social registra para la sociedad del salitre (diciembre de 1907), tuvo un impacto mínimo en las exportaciones de nitrato.

El empresariado salitrero en este periodo, si bien cambiaba de rostros, la colusión y las combinaciones habían producido una notoria endogamia que se reflejaba claramente en las escrituras notariales de diversas transacciones (ver Cuadro 4).

Una mirada más ilustrativa de estas relaciones económicas endogámicas se encuentra en el Gráfico 1.

1910 fue el último año de las combinaciones salitreras ${ }^{18}$. Como conclusión podemos repetir con T. O'Brien que "cuando la combinación colapsó, los seis más grandes salitreros británicos y alemanes contabilizaron un 50,39\% de la producción de salitre en Tarapacá. Un variado grupo de productores europeos más pequeño contabilizó otro $24,62 \%$. Bajo el régimen liberal de Chile, la competición desmedida había acelerado la concentración de capital para lograr la innovación y expandir la producción. Este proceso ejerció un control cada vez mayor sobre la industria en manos de una pequeña cantidad de productores que estaban al mando de los fondos necesarios para una gran inversión de capital fijo" (1982:60). Ese había sido el resultado de una concentración económica que surgió el mismo año que Chile firmó el Tratado de Ancón que le entregó soberanía plena sobre la principal provincia salitrera. Tarapacá. 
Cuadro 4. Compraventa de oficinas salitreras entre los años 1900 y 1913

\begin{tabular}{|c|c|c|c|}
\hline Fecha & Vendedor & Comprador & Objeto del Trato \\
\hline 30-11-1901 & Agustín Arrieta & Carmen de la Fuente & $\begin{array}{l}\text { La sexta parte de la Oficina } \\
\text { "Sebastopol" }\end{array}$ \\
\hline 23-12-1901 & Alfonso Vallebona & Carmen de la Fuente & $\begin{array}{l}\text { La sexta parte de la Oficina } \\
\text { "Sebastopol" }\end{array}$ \\
\hline 31-03-1913 & Antonio Viera Gallo & Andres E. Bustos & Oficina "Iquique" \\
\hline 22-03-1905 & $\begin{array}{l}\text { Clake, Bennet y Compañía, } \\
\text { Roberto Bridgford, Jhon Howard } \\
\text { Johnston y Lucy Constance James }\end{array}$ & $\begin{array}{l}\text { "The San Patricio Nitrate } \\
\text { Company Limited" }\end{array}$ & Oficina "San Patricio" \\
\hline 12-02-1902 & Daniel Oliva & "Folsch y Martin" & Oficina "Atacama" \\
\hline $12-?-1902$ & Daniel Oliva & "Folsch y Martin" & Oficina "Atacama" \\
\hline 24-11-1900 & David Richardson & $\begin{array}{l}\text { "Compañía de Salitres y } \\
\text { Ferrocarril de Junín" }\end{array}$ & $\begin{array}{l}\text { Oficina "Compañía", Establecimiento } \\
\text { "Cerro de Compañía" }\end{array}$ \\
\hline 18-03-1913 & El Banco de Chile Vende A & $\begin{array}{l}\text { "Baburizza, Bruna y Compañía" } \\
\text { y a don Augusto Bruna, don } \\
\text { Pascual Baburizza y José } \\
\text { Lukinovic }\end{array}$ & $\begin{array}{l}\text { Los terrenos salitrales que el banco } \\
\text { compró a la Cía. Salitrera Progreso } \\
\text { de Antofagasta divididos en tres } \\
\text { estacamentos que forman las Oficinas } \\
\text { "Ausonia", "Filomena" y "Aconcagua". }\end{array}$ \\
\hline 05-12-1903 & F.G. Clarke y Compañía & "Moro, Stiepovich Y Compañía" & $\begin{array}{l}\text { Un lote de terreno salitral llamado } \\
\text { "Santa Cruz", que forma parte de la } \\
\text { Oficina "San Patricio" }\end{array}$ \\
\hline 03-05-1912 & $\begin{array}{l}\text { Fidel Astoreca por "Astoreca y } \\
\text { Compañía" }\end{array}$ & Esteban Carcasson & $\begin{array}{l}\text { La Oficina "San Manuel", se compone } \\
\text { de } 3 \text { estacamentos: "Normandia", } \\
\text { "Dolores", "San Luis". }\end{array}$ \\
\hline 27-07-1901 & Gibbs y Cía. & Jorge Buchanan & Terreno Salitral "Pan de Azucar" \\
\hline 19-10-1910 & Guillermo Hardie & "Williamson, Balfour y Compañía' & $\begin{array}{l}\text { "El 75\% de la oficina "Keryma"; el 75\% } \\
\text { de la descubridora "Cerrito Blanco"; } \\
\text { el } 75 \% \text { de los derechos que tiene en la } \\
\text { Compañía Salitrera Remiendos; } 10.294 \\
\text { acciones de la Compañía Salitrera The } \\
\text { Fortuna Nitrate Company Limited }\end{array}$ \\
\hline 17-06-1902 & Isabel Ugarte & $\begin{array}{l}\text { A los Señores Ricardo R. Lockett, } \\
\text { Guillermo J. Lockett, Jorge A. } \\
\text { Lockett y Ricardo C. Lockett }\end{array}$ & Oficina "San Lorenzo" \\
\hline 24-12-1900 & Jaime Galté & Gil Galté & Terrenos Salitrales "Providencia" \\
\hline 22-05-1901 & $\begin{array}{l}\text { Juan Guillermo Carter, Carlos } \\
\text { Walker Martínez, Macario Ossa }\end{array}$ & Thomas Munerley & $\begin{array}{l}\text { Oficinas "Josefina", "Copiapina" y, en } \\
\text { Taltal, la "Aguada del Chaco" }\end{array}$ \\
\hline 10-11-1904 & Juan Loayza & Wilfrid Jordan Crewse & $\begin{array}{l}\text { Vende el derecho de dominio sobre } \\
\text { terrenos salitrales en el Cantón de } \\
\text { Zapiga que han formado la antigua } \\
\text { Oficina "Sacramento" }\end{array}$ \\
\hline 02-01-1913 & Juan Petricic & Luis J. Moro & Oficina "Hervatska" \\
\hline 01-06-1901 & Juan Vernal (vende su parte) & Alfonso Vallebona & Oficina "Sebastopol" \\
\hline 19-07-1906 & La Compañía Salitrera Alemana & "Clarke, Bennett y Cía." & $\begin{array}{l}\text { Todas sus propiedades salitreras de } \\
\text { Tarapacá (Virginia, Santa Ana, Cholita, } \\
\text { Yungay Bajo, Paposo y Limeñita) y de } \\
\text { Tocopilla (Santa Fe y otros) }\end{array}$ \\
\hline 01-12-1902 & $\begin{array}{l}\text { La Compañía Salitrera } \\
\text { San Esteban }\end{array}$ & "James y Lecaros" & Oficina "San Esteban" \\
\hline 01-11-1911 & $\begin{array}{l}\text { La Compañía Santa Rosa } \\
\text { Nitrate Company Limited }\end{array}$ & George Jeffery & La Oficina "Santa Rosa" \\
\hline 27-10-1911 & $\begin{array}{l}\text { La Sociedad Inglesa "The Santa } \\
\text { Rosa Nitrate Company Limited" } \\
\text { y sus acreedores hipotecarios }\end{array}$ & $\begin{array}{l}\text { "Compañía de Salitres y } \\
\text { Ferrocarril de Agua Santa" }\end{array}$ & $\begin{array}{l}\text { Oficina Salitrera "Rosario de } \\
\text { Negreiros" que consta de Tres } \\
\text { Estacamentos: "Rosario", } \\
\text { "La Chilena", "Germania" }\end{array}$ \\
\hline 21-10-1911 & $\begin{array}{l}\text { La viuda y herederos de Matías } \\
\text { Granja y "Granja y Cía." En } \\
\text { liquidación }\end{array}$ & Juan G. Searle & Oficina "Democracia" \\
\hline
\end{tabular}




\begin{tabular}{|c|c|c|c|}
\hline Fecha & Vendedor & Comprador & Objeto del Trato \\
\hline 07-11-1904 & Lacalle y Compañía & "Granja y Astoreca" & Oficina "San Manuel" \\
\hline 13-10-1905 & Lorenzo Cevallos & Federico Von Massenbach & Oficina "Sacramento", entre otras \\
\hline 21-02-1913 & Luis J. Moro & Antonio Viera Gallo & Oficina "Iquique" \\
\hline 20-03-1912 & $\begin{array}{l}\text { Luis J. Moro por si y en } \\
\text { representación de José Lukinovic } \\
\text { y de "Moro et Lukinovic" }\end{array}$ & Juan Petricic & Oficina "Hervatska" \\
\hline 26-07-1911 & $\begin{array}{l}\text { Luis J. Moro por si y en } \\
\text { representación de José Lukinovic } \\
\text { y de la sociedad "Moro et } \\
\text { Lukinovic" }\end{array}$ & $\begin{array}{l}\text { "Compañía de Salitres y } \\
\text { Ferrocarril de Junín" }\end{array}$ & Oficina "Sloga" \\
\hline 04-12-1901 & Luis W. Rawson & F.G. Clarke & $\begin{array}{l}50 \% \text { de las propiedades salitreras de } \\
\text { La sociedad "Rawson y Whitelegg" }\end{array}$ \\
\hline 04-10-1904 & Luis y Pablo Mitrovich & "The Alianza Company Limited" & $\begin{array}{l}\text { Un terreno salitral conocido como } \\
\text { "Slavonia" }\end{array}$ \\
\hline 10-09-1904 & Luis y Pablo Mitrovich & "Clarke, Bennett y Compañía" & Oficina "Vis" \\
\hline $13-12-1901$ & Matilde F. Whitelegg & F.G. Clarke & $\begin{array}{l}50 \% \text { de las propiedades salitreras de } \\
\text { La sociedad "Rawson Y Whitelegg" }\end{array}$ \\
\hline 26-07-1911 & $\begin{array}{l}\text { Mauro Lacalle por si y como } \\
\text { representante de la sociedad } \\
\text { "Lacalle Hermanos y Cía." }\end{array}$ & "Gibbs y Compañía" & $\begin{array}{l}\text { Los derechos o acciones que le } \\
\text { correspondan en la comunidad salitrera } \\
\text { Peñón }\end{array}$ \\
\hline 19-07-1904 & Pablo, Luis Mitrovich y Compañía & "Gildemeister y Compañía" & Oficina "Dalmacia" \\
\hline 03-04-1902 & Pedro Perfetti & $\begin{array}{l}\text { Compañía Comercial y } \\
\text { Salitrera "La Aguada" }\end{array}$ & Oficina "Tres Marías" \\
\hline 12-07-1902 & Salvador Pirretas & Alberto James & $\begin{array}{l}\text { La } 3{ }^{\text {a. }} \text { parte del terreno salitral llamado } \\
\text { "Terrenos en la Rinconada" (entre } \\
\text { Santa Elena y San Esteban) }\end{array}$ \\
\hline 19-10-1901 & $\begin{array}{l}\text { Sociedad "Vernal Hermanos" } \\
\text { y don Juan Vernal y Castro }\end{array}$ & $\begin{array}{l}\text { "Williamson, Balfour } \\
\text { y Compañía" }\end{array}$ & $\begin{array}{l}\text { Terrenos salitreros "Santa Rosa de } \\
\text { Huara" }\end{array}$ \\
\hline 25-07-1901 & $\begin{array}{l}\text { The Consolidated Nitrate } \\
\text { Company Limitada }\end{array}$ & "Gildemeister y Compañía" & $\begin{array}{l}\text { Oficinas "Sacramento", "San Carlos", } \\
\text { "Santa Lucía", "Santa Beatriz" }\end{array}$ \\
\hline 29-09-1911 & $\begin{array}{l}\text { The San Jorge Nitrate } \\
\text { Company Limited }\end{array}$ & "Gomez y Montes" & Oficina "San Jorge" \\
\hline 03-06-1904 & $\begin{array}{l}\text { The San Pablo Nitrate } \\
\text { Company Limited }\end{array}$ & Matías Granja & Oficina "Santa Rosa" \\
\hline 18-06-1904 & $\begin{array}{l}\text { The San Pablo Nitrate } \\
\text { Company Limited }\end{array}$ & George Jeffery & Faltan datos \\
\hline 26-11-1901 & $\begin{array}{l}\text { The Santa Elena Nitrate } \\
\text { Company Limited }\end{array}$ & "Inglis, Lomax y Compañía" & La Oficina Salitrera "Santa Elena" \\
\hline
\end{tabular}

Fuente: Fondo Documental del Salitre, Asociación Salitrera de Propaganda, documentos notariales, Vol. 1098, Archivo Nacional.

Para 1910, Alejandro Bertrand, el inspector fiscal de la propaganda salitrera en Europa y uno de los más versados especialistas del mercado internacional de las sustancias azoadas, publicaba su libro "La crisis del salitre", donde revisa precisamente los beneficios y perjuicios que esa concentración en la economía del nitrato. Posteriormente, en 1917, el propio Bertrand en otro libro recogió algunas reacciones sobre sus comentarios a los perjuicios de la concentración empresarial, una de ellas fue la del editor del semanario L' Engrais, M. Tibulle Collot, industrial agrícola, quien señaló: "Para el señor Bertrand los peligros que presentan las concentraciones del género Trust o Sindicato de ventas, han sido exagerados, como lo reconocen los autores de los estudios más recientes publicados sobre esta materia. Particularmente el alza de precios originada por los procedimientos de un sindicato no son de carácter permanente, sino cuando corresponden verdaderamente a una necesidad industrial, es decir, cuando la depresión anterior de los precios era demasiado fuerte para permitir a la industria continuar soportándola. En resumen, siempre es posible reglamentar los abusos del poder sindical dignos de preverse, puesto que el Gobierno de Chile está directamente y grandemente interesado en la cuestión" (Bertrand 1917:181). Es decir, hacia 1910 y en los años siguientes todavía se discutía sobre la utilidad de una combinación para la industria del salitre, en palabras de Collot, "si el tipo de Sindicato puede hacerla más próspera, respetando 
Gráfico 1.

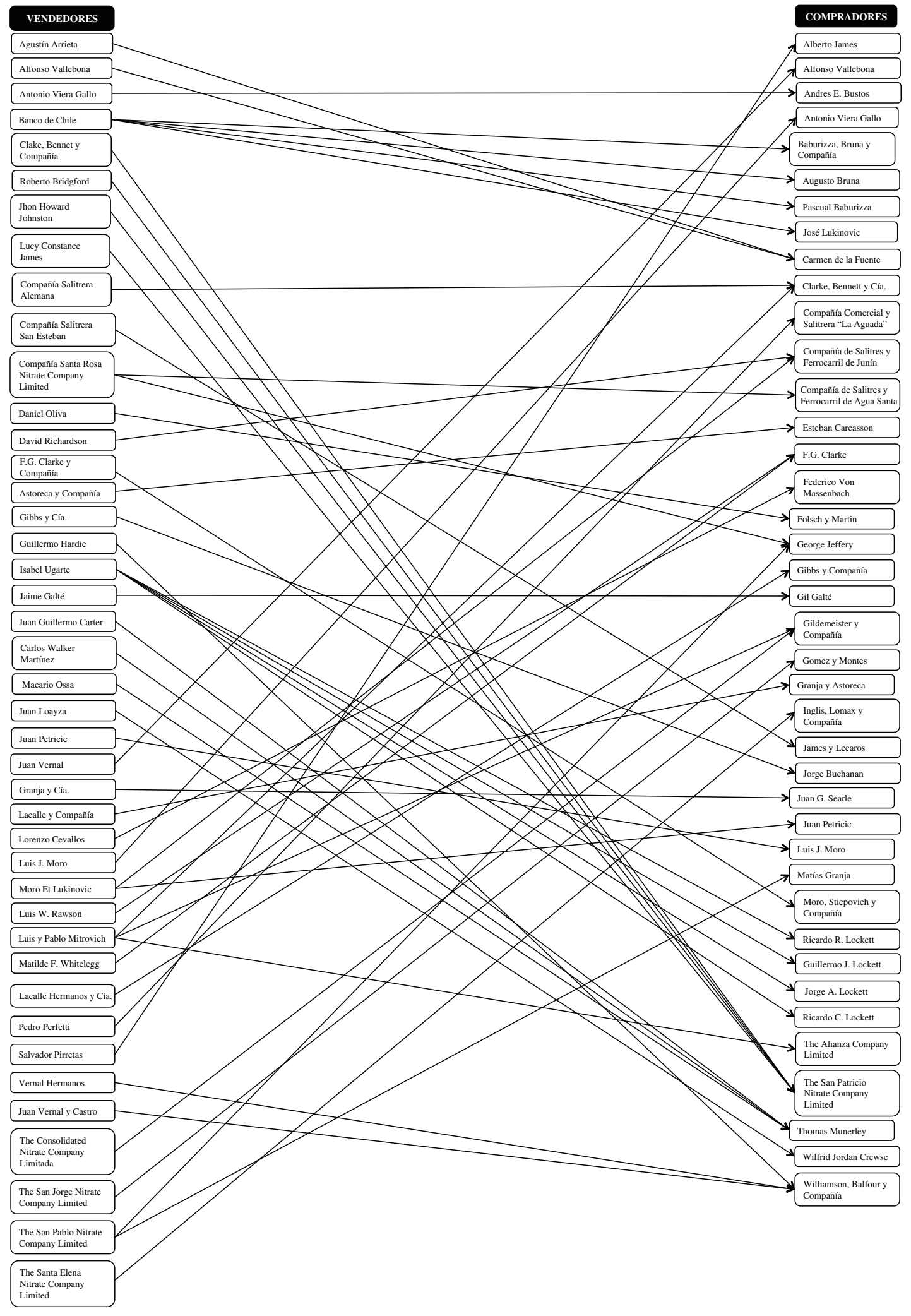


al mismo tiempo los intereses del consumo, el porvenir de una industria tan útil, exige que se estudie esta combinación" (Bertrand 1917:181). Sin embargo, por las voces críticas que comenzaban a cuestionar las colusiones y la influencia inglesa, pero sobre todo porque el nitrato chileno había, para esa época, notoriamente perdido la competencia con los otros nitratos, especialmente con los salitres artificiales, las combinaciones dejaron de existir.

Con relación a la resistencia cada vez mayor al capital extranjero del salitre, después de casi treinta años de hegemonía del capital inglés, vemos en 1912 al Consejo Salitrero defendiendo al Comité de Londres de rumores que, junto a la Asociación Salitrera de Propaganda, ocultaban las cifras relativas a la industria del salitre, señalando que publicaban boletines sobre todas las ventas y negocios salitreros, "el Comité de Londres ha manifestado un propósito enteramente contrario al de ocultar hasta el nombre del país en que se produce el salitre, al cambiar su título antiguo que el de Permanent Nitrate Committee, por el de Chilean Nitrate Committee que lleva en la actualidad" (Consejo Salitrero 1913:IX). El centenario de la República abrió las puertas a críticas hacia lo extranjero, donde los capitales salitreros y sus resistidas combinaciones no podían quedar al margen por su notoriedad, y un cambio de nombre no sería suficiente para revertir el cuestionamiento. Como tampoco lo fue el cambio en 1919 de la Asociación Salitrera de Propaganda porde Productores de Salitre de Chile.

Alejandro Bertrand denunció que los especuladores eran los que fijaban los precios del nitrato chileno, generando una peligrosa inestabilidad que afectaba la compra, pues los agricultores preferían un producto, aunque fuese más caro o menos eficaz, les permitiese planificarse al tener un precio estable, nos dice este autor: "La opinión general, entre los directores en Europa de compañías productoras, es que esas fluctuaciones proceden del hecho de que, con la organización actual de ese comercio son los especuladores los que fijan los precios, se entiende los precios de estación o temporada, y no opera sino a la larga la ley natural de la oferta y la demanda. Según lo veremos más adelante, las combinaciones salitreras no han tenido, como podían tenerla, ninguna acción en la estabilización de los precios, pues no han sido, como lo expresó muy bien uno de aquellos directores, sino combinaciones incompletas que han aprovechado únicamente los especuladores"
(1910:21). Porque no fue el precio el fin último de las combinaciones, sino la propia necesidad de actuar unidos para evitar competencia en la región productora y así invertir escaso capital en tecnologías aprovechando una mano de obra barata y las mejores pampas calichales del país.

Bertrand percibió vientos de crisis para el salitre, entre otras razones, porque vio el desarrollo de los productos competitivos en Europa, por lo tanto, sugirió un cambio de política salitrera al Gobierno chileno. Este especialista creía que existían antecedentes suficientes para que la industria y comercio salitreros se reorganizaran y, apoyado en la opinión de algunos especialistas, afirmó: "la opinión ilustrada en Chile reconoce que el Estado tiene derecho a intervenir en esa organización y exige unánimemente que se ejerza ese derecho. Que otras naciones, de las más civilizadas y progresistas, se ha adelantado a señalar la iniciativa que le corresponde tomar a un gobierno deseoso de conservar a su país el beneficio del privilegio económico que le ha otorgado la naturaleza en la forma de un producto que no existe sino en su suelo" (1910:73). Esta propuesta de un empleado público honesto, como Bertrand, no sería bien acogida en Chile.

El propio Bertrand, precisamente, es quien resume el problema de la crisis del salitre (1915), de modo magistral: "la idea de una rebaja posible de exportación del salitre es considerada como inaceptable por parte de gran parte de la opinión política en Chile; precisamente porque la idea de la intervención del Gobierno en la fijación de los precios y de la producción anual del salitre, sería considerada como no menos inaceptable por la Asociación de Productores" (1915:12). Es decir, nuevamente el viejo dilema de 1880: la libertad empresarial solo regulada por un impuesto a la exportación o el Estanco salitrero del Estado nacional.

En 1916 se presentó el primer proyecto de ley para la organización de la industria del salitre en una sola Asociación que controlara las ventas. En 1919, año de profunda crisis, el directorio de la Asociación de Productores podía fijar los precios de venta del salitre. ¿se volvía al viejo estanco salitrero?

\section{Agradecimientos}

Agradezco a mi ayudante Fondecyt Renato Calderón Gajardo por su aporte en el registro de información y por sus opiniones al borrador de este escrito. 


\section{Referencias Citadas}

Aldunate Solar, C.

1907 Leyes, decretos i documentos relativos a salitreras, Santiago, Chile: Imprenta Cervantes.

Bertrand, Alejandro

1917 Evolución de las industrias del azoe. Litografía e Imprenta Moderna, Valparaíso.

1910 La crisis salitrera. Estudio de sus causas y caracteres y de las condiciones favorables que caracterizan a la industria y comercio del salitre, Paris, Francia: Editor Louis Michaud.

1915 Industria y comercio de sustancias azoadas. Sociedad Imprenta y Litografía Barcelona, Valparaíso-Santiago.

Bourdieu, P. y Passeron, J.C.

1970 La Reproduction. Ed. de Minuit, París.

Cariola C. y Sunkel, O.

1991 Un siglo de Historia económica de Chile, 1830-1930. Editorial Universitaria, Santiago.

Combinación Salitrera

1900 Escrituras públicas de la Combinación Salitrera de 1901 a 1906. Imprenta de La Patria, Iquique.

Consejo Salitrero

1913 Actas de las sesiones celebradas por el Consejo Salitrero durante el año 1912. Imprenta, Litografía y Encuadernación Barcelona, Santiago.

Le Feuvre, R. y Dagnino, A.

1893 El salitre de Chile o nitrato de soda. Imprenta Cervantes, Santiago.

Merton, R.K.

1977 Sociología de la Ciencia, Edit. Alianza, Madrid.

Ministerio de Hacienda

1935 La Industria del Salitre de Chile. Tomo I, Santiago.
O'Brien, Thomas

1982 The nitrate industry and Chile's crucial transition: 1870-1891, New York, USA: University Press.

Oliván, Francisco

1893 La Combinación Salitrera: sus hechuras y lo que puede suceder. Tipografía Central, Valparaíso.

Reyes, Enrique

1973 El desarrollo de la conciencia proletaria en Chile (el ciclo salitrero). Editorial Orbe, Universidad del Norte, Santiago.

1985 "El mercado mundial del salitre”. Revista Nueva Historia, núm. 15-16, año 4, pp. 181-214.

Schmidt, H.G.

1884 Memoria i Proyecto del presidente del Comité Salitrero sobre la propagación del consumo del salitre, Iquique, Chile: Imprenta de El Veintiuno de Mayo.

Semper, E. y E. Michels

1908 La industria del salitre en Chile, Santiago, Imprenta, Litografía y Encuadernación Barcelona.

Valdés Vergara, F.

1884 Memoria sobre la administración de Tarapacá presentada al Supremo Gobierno, Santiago, Chile: Imprenta de La República.

\section{Fuentes}

Fondo Documental del Salitre, Asociación Salitrera de Propaganda, documentos notariales, Vol. 1098, Archivo Nacional.

\section{Periódicos}

Libertad Electoral, El Heraldo, El Mercurio, El Nacional de Iquique, El Ferrocarril, La Patria, La Unión de Valparaíso (entre 1884 y 1896).

\section{Notas}

1 También hubo combinaciones del yodo.

2 Según Alejandro Bertrand "el ázoe salitrero exportado por Chile no representa ya, en 1914, sino el 55\% de todo el ázoe inorgánico puesto en el mercado" (1915:4), sin considerar a los fertilizantes orgánicos. Hubo un intento en 1913 de organizar una Cmbinación salitrera, pero fracasó por falta de concenso.

3 Fuente: Ministerio de Hacienda. La Industria del Salitre de Chile. Tomo I, Santiago, 1935, p.7.

4 Este fue el concepto que se utilizó más recurrentemente entre los opositores de las combinaciones (La Libertad Electoral 1893).

5 La conducta de los tenedores de bonos y certificados que no accedieron a salitreras o estacamentos la hemos analizado en el otro artículo.

6 Merton define el ethos como un complejo de valores y normas, con tintes afectivos, que se considera obligatorio para el hombre que lo profesa. El ethos le permite al sujeto orientarse y tener un punto de vista sobre la realidad, no exento de un sentimiento de adscripción a esas normas y valores. Merton se refiere a la ciencia y al hombre de ciencia (Merton 1977).

7 La Compañía de Salitres y Ferrocarril de Antofagasta, fundada en 1872, continuadora de la Milbourne Clark y $C^{\circ}$.
8 El pensamiento económico específico del empresariado salitrero se manifestó en documentos como los Memoriales de los patrones de 1904, en el contexto de la visita parlamentaria de ese año a las regiones de Tarapacá y Antofagasta.

9 Este decreto identificó 103 salitreras que debían ser rematadas.

10 Estos tenedores demandaron al Estado de Chile por el perjuicio que sufrieron al no acceder a la industria o terrenos salitreros que, señalaban, esos certificados les daban derecho.

11 Quien fuera cónsul en Japón y encargado de la propaganda salitrera en el Asia.

12 La crítica realizada por la administración chilena a la política peruana salitrera incluyó no solamente a la ley de expropiación, sino también al estanco del salitre, sin embargo, será el estanco la salida que los especialistas propusieron como salida a la crisis en la década de los años de 1920.

13 La Combinación Salitrera que se constituyó en 1891, en plena Guerra Civil, no estableció cuotas de producción, sino meses de producción, a saber:

"Los infrascritos, todos productores de salitre, convienen en formar parte de una combinación salitrera, por el término de dos años, contados desde el $1 .{ }^{\circ}$ de Enero de 1891, con arreglo a las siguientes estipulaciones:

1. ${ }^{\circ}$ Cada uno de los firmantes de este convenio, en el carácter en que comparece o por la sociedad que representa, 
conviene que los demás otorgantes en no trabajar en sus respectivas oficinas salitreras, sino siete meses en el año 1891, y se obliga del mismo modo a suspender por completo la elaboración por cinco meses en el mismo año en la forma siguiente:

Cada productor podrá elegir los siete meses de elaboración que le convinieren, dando un aviso anticipado por escrito de quince días a lo menos, al consejo directivo de la combinación, cada vez que principie o suspenda el trabajo; no pudiendo hacerse estas operaciones sino el $1 .^{\circ}$ o el 15 de cada mes. El productor que eligiere en la forma dicha los siete meses de trabajo que le convenga, deberá suspender por completo la elaboración durante los últimos cinco meses del presente año.

$2{ }^{\circ}$ El número de meses que durará la elaboración en 1892, será fijado por el Consejo Directivo de la combinación; y sujetándose a esta fijación, cada productor podrá elegir los meses de elaboración en la forma y condiciones estipuladas en el artículo $1 .^{\circ}$

$3 .^{\circ}$ La suspensión de trabajo se refiere únicamente a la elaboración de salitre, pudiendo, en consecuencia, extraerse y acumularse caliche durante la paralización.

$4 .^{\circ}$ Los firmantes de este convenio pagarán al Consejo Directivo, la cuota que este juzgue necesaria para atender a los gastos de propagación de consumo de salitre, y a los que demanden el sostenimiento y la administración de la combinación; no pudiendo dicha cuota exceder de medio centavo por quintal de salitre embarcado.

$5{ }^{\circ}$ Cualquier productor que elabore salitre fuera de los períodos a que tenga derecho según este convenio, pagará por cada día de exceso una multa, cuyo monto será fijado en los estatutos y que ingresará a fondos comunes de la combinación, sin prejuicio de obligársela paralizar la elaboración por el tiempo que corresponda (...).

(La Patria, 7 de abril de 1891).

14 Para revisar leyes y decretos relativos a la economía salitrera ver (Aldunate Solar 1907).

15 Este problema fue latamente denunciado y estudiado por Alejandro Bertrand, a saber: "si a estas oscilaciones tan intensas como violentas en el precio del salitre se agregan las no menores del cambio de la moneda chilena sobre Londres, queda de manifiesto el ancho campo que ofrecen a la especulación todas las transacciones que origina el comercio del salitre" (1910:21).

16 Como delegado de Europa del Gobierno de Chile para la inspección de los servicios de propaganda salitrera,
Alejandro Bertrand, defendió los gastos fiscales en esta acción de penetración del nitrato chileno en nuevos mercados y consolidación de los tradicionales, lo que no siempre fue bien comprendido (ver actas del Consejo Salitrero 1912).

17 Escritura Pública General del Convenio de la Combinación Salitrera. Iquique, 24 octubre de 1900. Notaría: Francisco Martínes Gálvez.

Art $3^{\circ}$. La exportación total en cada uno de los años salitreros siguientes será fijada por el directorio y avisada a los productores a más tardar el 15 de mayo de cada año; sin embargo, podrá ser modificada, a más tardar, en la primera semana de julio de cada años, si así lo acuerda un número de Asociados que represente a lo menos el $65 \%$ del total de las cuotas de las Oficinas según el cuadro...

Art $5^{\circ}$. El directorio tendrá la facultad de fijar, a más tardar, el 15 de mayo de cada año la proporción de lo que convenga exportar en los nueve meses de abril a diciembre de cada año... Art $6^{\circ}$. La cuota anual de exportación de cada Oficina en el primer año de este Convenio será asignada en el Cuadro General de todas las Oficinas que se suscribirá en escritura pública adicional...

At $7^{\circ}$. Dicho Cuadro servirá de base para fijar las cuotas de exportación a cada una de las Oficinas en los cuatro años siguientes de este Convenio...

Art. $8^{\circ}(\ldots)$ La relación entre cada cuota y el total que suma el Cuadro (...) da el porcentaje que corresponda a cada una de las Oficinas, sin excepción, en la cifra de exportación general fijada...

Art 14. La Oficina que no exporte la totalidad de su cuota en el años salitrero podrá embarcar el saldo en el año siguiente, pero sólo en el caso que lo haya elaborado en el año anterior. Art. 15. Ningún productor podrá elaborar en caso alguno en el año salitrero más del $15 \%$ de su cuota anual de producción, sin incurrir en una multa de seis peniques esterlinas por cada quintal español de exceso...

Art. 17. El Directorio nombrara comisiones que verificarán la existencia de salitre tanto en las Oficinas como en camino y en los puertos al fin de cada año salitrero...

Artículo transitorio:

A.- El Directorio de la Asociación Salitrera de Propaganda hará tomar la existencia de salitre de todas y cada una de las Oficinas el 31 de diciembre de 1900. Dichas existencias será de libre exportación de enero a marzo de 1901.

18 Hacia 1910 Alemania era el principal consumidor de nitrato de soda (750.000 toneladas), seguido de Estados Unidos (524.000 ton.), Francia (337.000 ton.), Bélgica (140.000 ton.), Reino Unido (120.000 ton.) (Bertrand). 